\title{
Un ajuste de cantos: a lírica trobadoresca e a renegociación dos roles de xénero na poesía portuguesa contemporánea
}

\author{
Paulo Alexandre Pereira \\ Universidade de Aveiro \\ https://orcid.org/0000-0003-2539-4248
}

[Recibido, 2 outubro 2020; aceptado, 15 novembro 2020]

[Pereira, P. A. (2020). Un ajuste de cantos: a lírica trobadoresca e a renegociación dos roles de xénero na poesía portuguesa contemporénea. Boletín Galego de Literatura, 57, "Estudos", 67-91]

DOl http://dx.doi.org/10.15304/bgl.57.7147

RESUMO Mesmo que intermitente, a presenza da memoria trobadoresca na poesía portuguesa dos séculos XX-XXI permite identificar un contínuum intertextual que non deixa dúbidas sobre a impresionante posteridade do repertorio poético medieval. A resemantización da tradición lírica peninsular da Idade Media -e, en particular, da cantiga de amigo-, ilustrada polas súas moitas reescrituras contemporáneas, documenta a plurifuncionalidade -retórica, ideolóxica, simbólica- dunha poesía que non deixou de interpelar creativamente, alén daquel que foi o seu tempo de vixencia histórico- periodolóxica. No presente artigo, partindo da análise de poemas seleccionados de autoras portuguesas contemporáneas de diferentes xeracións -Maria Teresa Horta, Natália Correia, Ana Luísa Amaral, Adília Lopes e Catarina Nunes de Almeida-, discútese o modo como, a través das réplicas poéticas que todas concibiron para as cantigas de amigo, conseguen deconstruír a "política sexual" do xénero medieval, converténdoo en vehículo dun gender trouble contemporáneo.

PalABRAS CHAVE: Cantiga de amigo; poesía portuguesa contemporánea; xénero sexual; xénero literario.

ABSTRACT Although the memory of troubadour poetry only surfaces intermittently in $20^{\text {th }}$ and $21^{\text {st }}$ century Portuguese poets, its persistence gives evidence of an intertextual continuum, leaving no doubt as to the impressive posterity of medieval poetic tradition. The retextualization of the Iberian lyrical genres - particularly that pertaining to the cantiga de amigo-, as illustrated by numerous poetic pastiches and parodies, gives evidence of the rhetorical, ideological and symbolic versatility of a poetic legacy that has never ceased to instigate (re)creation, well beyond its time of composition and circulation. In this article, drawing on the analysis of selected poems by female Portuguese contemporary poets belonging to different generations -Maria Teresa Horta, Natália Correia, Ana Luísa Amaral, Adília Lopes, and Catarina Nunes de Almeida-, we discuss the ways in which, by poetically replying to the medieval cantiga de amigo, they have succeeded in disrupting the "sexual politics" underlying this poetic genre, making it voice contemporary gender trouble.

KEYWORDS: Cantiga de amigo; contemporary Portuguese poetry; gender; genre. 


\title{
Un ajuste de cantos
}

Nunha das súas moitas artes poeticae, anti-retóricas e saturadas de xogos de palabras, Adília Lopes, quen se autodenomina como a "poetisa pop" portuguesa -cuxas variacións neotrobadorescas analizarei neste traballo- describiu a obra de arte como un "ajuste de cantos":

\author{
A obra de arte \\ não é um ajuste \\ de contas \\ é um ajuste \\ de cantos. (Lopes, 2009, p. 269)
}

A propósito da noción de axuste de Lopes e usándoa con liberdade como un tropo aclaratorio, o meu propósito é botar luz sobre a operación estética e ideolóxica de conxunción das dúas tradicións poéticas sobre as que versa o estudo: a lírica medieval galego-portuguesa e a poesía contemporánea portuguesa. Para a meirande parte dos poetas contemporáneos, que foron no seu día engaiolados e retados creativamente pola alquimia verbal minimalista das cantigas peninsulares, o axuste (entendido como a conciliación do ton e estilo da voz poética descarnada e vestixial do trobador e a súa propia dicción) foi certamente unha cuestión fundamental.

Neste artigo, indagarei a ocasional -mais evidente- pegada da tradición lírica medieval da Península Ibérica en poetas contemporáneos selectos, entendida como o resultado dun acto discursivo e de converxencia afectiva a través do cal as voces medievais e contemporáneas foron mutuamente axustadas. Como se esperaba, o axuste resultante deste encontro estético pode ter sufrido certa resistencia momentánea e fricción, e a sedución temática e formal ou o axuste ideolóxico dun poeta contemporáneo á poética trobadoresca pode ter sido acompañada por unha firme réplica ás premisas ideolóxicas que a subxacen.

Afastados da constancia arqueolóxica ou da forte tendencia política doutros movementos neo-trobadorescos -como o estilo trobadoresco da Restauración Francesa do século XIX ou o neotrobadorismo galego, o cal emerxeu a comezos do século XX, "when avant-garde experimentalism was torn by a constant tension between new and traditional forms" (Gutiérrez García, 
2014, p. 29)- os poetas portugueses non estaban interesados en revitalizar programaticamente a memoria formal da poesía medieval e a súa atracción polo repertorio trobadoresco foi intermitente. Polo tanto, dificilmente podería terse considerado esta revivificadora e irregular remembrance -tomando prestada a palabra medieval utilizada por Nathalie Koble e Mireille Séguy na presentación dun monográfico acerca da memoria da Idade Media na poesía contemporánea (Koble e Séguy, 2014, p. 7) ${ }^{1}$ - como un movemento literario ou inclusive unha tendencia recoñecible.

É indiscutíbel que, para os autores portugueses e galegos post-medievais, a recepción filolóxica e a creativa da poesía trobadoresca estiveron sempre intimamente relacionadas. Como apunta Gutiérrez García (2014, p. 28), "the first step in this process of recognition -and reappropriation- of the past was the discovery of the Galician-Portuguese cancioneiros in the mid-nineteenth century, which placed an emerging nationalist literary historiography in Galicia on a par with other national literary traditions across Europe", suscitando "the artistic assimilation of the poetic resources of the medieval lyric right up until the early decades of the early twentieth century". De orixes dispares e cunha intencionalidade ideolóxica desigual manifesta, a inspiración neo-trobadoresca en Portugal e Galicia beneficiouse, durante as primeiras décadas do século XX, dos intercambios literarios ocasionais promovidos por autores individuais, tales como o poeta portugués Afonso Lopes Vieira (1878-1946), cuxos pastiches neo-trobadorescos foron admirados e imitados con posterioridade polos intelectuais nacionalistas galegos na década de 1920. Aínda que frutíferos, estes contactos que involucraron a autores portugueses e galegos, impulsados por unha axenda nacionalista igualmente compartida polas persoas asociadas ao movemento saudosista e á Xeración Nós, nunca chegou a culminar na constitución dunha tendencia estética consistente na poesía portuguesa.

No seu amplo estudo histórico do neotrobadorismo galego, Teresa López (1997, p. 133) sostivo con acerto que nas literaturas portuguesa e brasileira,

1 Logo de recordar que "la littérature em langue française qui se constitue au Xle et au Xlle siècles s'est explicitement pensée comme une enterprise de 'remembrance', ce terme étant à lire dans les deux senses de rémemoration et de remembrement ( $c$ 'est-à-dire de ré-articulation)", Koble e Séguy apuntan acertadamente que "la mémoire du Moyen Âge aujourd'hui à l'oeuvre dans la poésie contemporaine rejoint la mémoire telle qu'elle s'entendait au Moyen Âge, comme une pratique à la fois sérieuse et ludique - vitale" (Koble e Séguy, 2014, p. 7). 
os contextos literarios nos cales sería máis presumíbel a reciclaxe dos modelos trobadorescos de xeito evidente, a poesía neotrobadoresca nunca foi cuantitativamente relevante, nin con respecto ao número de autores nin á proporción de textos de inspiración medieval na súa obra² ${ }^{2}$ Nunha reaproximación máis recente ao tema en cuestión, Martínez Pereiro (2014, p. 93) argumentou de xeito similar que a dispersión e a falta de "teimosía escritural" fixo que sexa máis axeitado falar de textos trobadorescos no lugar de autores en Portugal e Brasil.

De xeito descontinuo e discreto, perdendo así a posibilidade da cohesión xeracional e doutrinal, a influencia da tradición lírica medieval na poesía portuguesa dos séculos XX e XXI tivo unha salientábel perdurabilidade, conxugando un gran grupo de autores de períodos e xenealoxías dispares. Un nacionalismo literario dominante e unha obsesión fetichista coa portugalidade podería ternos permitido a afiliación á creatividade poética neomedieval de autores como Afonso Lopes Vieira, António Sardinha ou Afonso Duarte. De xeito similar, a oposición política antiditatorial e a protesta pacífica poderían considerarse como os denominadores comúns sobre os que se asentan as variacións da poética neotrobadoresca de Manuel da Fonseca, Fernando Namora, Fiama Hasse Pais Brandão ${ }^{3}$ ou Manuel Alegre. Algúns poemas de Maria Teresa Horta, Natália Correia ou Ana Luísa Amaral poderían, como será argumentado posteriormente, ser interpretados como reescrituras feministas disruptivas de xéneros poéticos medievais levadas a cabo polas herdeiras posmodernas da figura da trobairitz.

2 Na conclusión da pioneira tese de doutoramento realizada por William Myron Davis sobre o neo-trobadorismo en Brasil, Portugal e Galicia, o autor xa resaltou que, a pesar da "objective proof of the existence of this specific type of neo-medievalism among many twentieth-century poets in Galicia, Portugal, and Brazil, to an extent hitherto unsuspected", "the chief problem, that of general configuration, remains". Polo tanto, conclúe que "Neo-troubadourism represents at the very least a sporadic tendency in Portugal and Brazil, and perhaps trend in Galicia" (Davis, 1969, p. 256).

3 A débeda de Fiama coa tradición trobadoresca faise explícita a través da intermitente, pero prolongada reutilización da atípica cantiga de amor de Joham Zorro "En Lixboa, sobre lo mar": nomeou de maneira significativa como Barcas Novas a colección de poemas que a poetisa publicou en 1967, e titulou O Texto de João Zorro a primeira compilación da súa obra poética que saíu en 1974. Ademais, a coñecida cantiga na que o jogral portugués desenvolvía o motivo militar das barcas novas foi utilizada como epígrafe do poema político homónimo de Fiama no que, por analoxía histórica, se evocaba a saída dos soldados durante as guerras coloniais portuguesas. Amais, o rumbo androcéntrico e homossocial do poema de Fiama móstrase de forma bastante reveladora, por exemplo, na mención única dos «homens". 
Con todo, estes supostos parecidos familiares non son suficientes para suavizar a inefábel variedade de modismos poéticos e o uso idiosincrático que cada autor fai dunha tradición medieval común, unha reserva compartida de imaxes e temas que a miúdo se senten tentados a utilizar, aínda que en grao variábel e por razóns e propósitos extremadamente diversos ${ }^{4}$. Noutras palabras, aínda que o estabelecemento dunha tipoloxía dos usos do neotrobadorismo na poesía contemporánea, xa sexa seguindo unha periodización literaria ou criterios formais (é dicir, tratando de avaliar o grao de similitude ou desviación entre o paradigma medieval e a súa imitación contemporánea) pode resultar operativo, a reelaboración idiolectal dos xéneros e motivos trobadorescos fai que sexa imperativo examinar tamén as motivacións ideolóxicas que subxacen aos procesos de renovación neomedieval. Así pois, todos os modos de recepción medieval distinguidos por F. Gentry e U. Müller (1991) no seu estudo xa clásico (produtivo, reprodutivo, académico e político-ideolóxico) están, en todas as versións do renacemento neotrobadoresco, inextricabelmente vinculados e todos eles son, por tanto, dunha relevancia incuestionábel cando se tenta dar conta plenamente destes encontros intertextuais.

Nesta ocasión, con todo, optei por centrarme máis especificamente na dimensión político-ideolóxica do medievalismo, é dicir, naqueles casos en que "medieval works, themes, 'ideas' or persons are used and 'reworked' for political purposes in the broadest sense, e.g., for legitimization or for debunking" (Gentry e Müller, 1991, p. 401). Abordarei as cuestións relativas á política sexual contemporánea, tratando de exemplificar algunhas das formas nas que os poetas portugueses contemporáneos, ao reivindicar de maneira innovadora a tradición da poesía medieval galego-portuguesa, se propoñen volver concibir os papeis dos xéneros, deconstruír as mitoloxías esencialistas da feminidade e a masculinidade e socavar as identidades de xénero asignadas. De maneira máis sinxela, tratarei de mostrar como, coa axuda insospeitada dos trobadores, os poetas dos séculos XX e XXI lograron expresar gender troubles moi contemporáneos.

4 As observacións de Pérez Priego sobre a presenza de temas e motivos medievais na poesía española contemporánea poderían, mutatis mutandis, aplicarse ao caso portugués. Na súa opinión, "lo medieval ocupa un lugar, cierto, en la atención de los poetas modernos. Pero es un lugar más bien recóndito, muchas veces generoso alarde cultural. Hay, sí, imitaciones conscientes, descubrimientos que ocasionalmente deslumbran al creador moderno. Pero sus preocupaciones artísticas, lógicamente, van por otros caminos. Lo que sí es cierto es que el poeta moderno no ha renunciado a la Edad Media, a la literatura medieval. La siente en su tradición literaria, forma parte como él de la misma historia literaria. Ello le permite apreciarla, valorarla y traerla tantas veces a su presente, recreándola e incluso modificándola" (Pérez Priego, 2006, p. 58). 


\section{A canción de muller peninsular e o debate sobre o xénero}

Non é de estrañar que os xéneros poéticos medievais galego-portugueses, e en particular as cantigas de amigo, cultivadas entre finais do século XII e mediados do XIV por máis de 150 poetas afiliados ás cortes de Castela, León, Galicia e Portugal, estean no centro do labor poético arqueolóxico de varios autores portugueses contemporáneos. O fragmentario e anónimo Arte de Trovar, o breve tratado retórico adxunto a unha das coleccións poéticas existentes, o Cancioneiro da Biblioteca Nacional, enumeraba, nunha tripartición un tanto simplista, os xéneros canónicos -cantigas de amor, cantigas de amigo e cantigas de escárnio e maldizer - a través dos cales se distribúen máis de 1500 textos sobreviventes.

Aínda que os límites que separan os dous xéneros de amor (cantigas de amor e cantigas de amigo) se establecen en termos de enunciación (masculino e feminino, respectivamente), a distinción das dúas subclases satíricas incluídas na categoría híbrida de escarnio e maldicir faise sobre a base dun criterio estilístico, dependendo de se os poetas recorren a termos obscenos encubertos ou explícitos nas súas invectivas e sátiras. Os críticos chamaron a miúdo a atención sobre as limitacións operativas e as incoherencias clasificatorias

72 desta disposición triádica, nas que non vou profundar neste traballo.

Con todo, vale a pena lembrar que a dicotomía vocal home/muller se atopa no corazón dos límites do xénero dos que informa a práctica do trobador coetáneo. Non sería inexacto suxerir que a recepción posmedieval das cantigas galego-portuguesas aceptou até as últimas décadas con credibilidade esta fabricación vocal, dando por certo que a voz do poeta masculino, que se fixo oír na versión peninsular do canso occitano, era totalmente distinta da da inxenua doncela que, con enganosa franqueza, falaba motu proprio na cantiga de amigo. Debido a que "the male-authored cantigas de amigo create a dynamic notion of femininity whose multiple and even contradictory roles, voices, and emotions contrast with the uniformity and monotony created for the female figure in the male-voice cantigas de amor" (Corral, 2002, p. 81), os lectores modernos aceptaron facilmente esta enganosa alteridade, e a súa voluntaria suspensión da incredibilidade axudou a borrar da memoria o funcionamento da ventriloquia transexual indirecta que fixo xerar o Ersatz andróxino do poeta escoitado na cantiga de amigo ${ }^{5}$.

5 Graça Videira Lopes resume con agudeza as consecuencias pragmáticas do efecto de realidade que logran os poetas masculinos cando recrean artisticamente a voz feminina na 
Aínda así, como sinalou acertadamente Rip Cohen (2003, p. 31), o corpus das cantigas de amigo peninsulares, que comprende máis de 500 textos, é "the largest body of female voiced love poetry that has survived from medieval or ancient Europe", e un "still mainly unexplored source for the study of the history of woman's voice, that is, speech, law, sexuality, mentality (however much that voice may be manipulated, archaic social, linguistic and musical features in these poems suggest that it is genuine in its origins)". Combinado estratexicamente co mito da feminidade xenética (é dicir, a ilusión retórica de que no poema falaba unha muller real e que podería ser, con toda probabilidade, a súa autora empírica ${ }^{6}$ ), o mito da creación (romántica) de orixe autóctona marcou o camiño interpretativo da cantiga de amigo, á que, dende o século XIX, e máis notabelmente baixo a influencia das tendencias nacionalistas vixentes nas primeiras décadas do século $\mathrm{XX}$, se lle deu maior relevancia, tanto en termos de recepción crítica como creativa ${ }^{7}$.

Cooptada polas fantasías nacionalistas bárdicas e usualmente lida como Volkspoesie, baixo o irresistíbel feitizo da falacia de sinceridade antes mencionada, non é nada sorprendente que até hai moi pouco a cantiga de amigo galego-portuguesa non fose obxecto de lecturas feministas destinadas a localizar instancias da mesma orde patriarcal homosocial que deu forma tanto ao canso occitano como ao seu subproduto peninsular, a cantiga de amor. Aínda que as perspicaces observacións de Tavani sobre a complementariedade in-

cantiga de amigo: "Convém lembrar, antes de mais, uma coisa simples e que é ser este um género onde o efeito de real é notável, ou seja, nestas cantigas o ouvinte ou o leitor parecem ouvir diretamente uma voz feminina (ou várias), sem mediação ou interferências. Mesmo sabendo que as cantigas são todas da autoria de trovadores e jograis, o facto é que essa autoria masculina parece apagar-se sem deixar marcas, a tal ponto a voz feminina se impõe como real ou verosímil" (Videira Lopes, 2018, p. 343).

6 Aquí refírome, obviamente, á clásica distinción de Bec (1979, pp. 235-262) entre "féminité génétique" e féminité textuelle". Para un recente e estimulante reexame dos argumentos de Bec, véxase o estudo de A. R. Roque no que a autora sostén que a oposición de Bec non debería impedir unha lectura comparativa dos textos de autoría e voz femininas incluídos na categoría multiforme da chanson de femme, xa que "é precisamente o facto de o género sexual do trovador não coincidir com o do sujeito lírico a que dá voz que garante grande parte do interesse e do encanto da cantiga de amigo" (Roque, 2018, pp. 371-372).

7 Cómpre dicir que, entre as recreacións musicais realizadas por varios compositores portugueses de renome (Tomás Borba, Frederico de Freitas, Cláudio Carneyro, entre outros) para a Exposición Universal de Portugal de 1940, só atopamos cantigas de amigo. Sobre o tema, ver Lopes, 2018, p. 340. A exposición foi organizada polo réxime autoritario portugués de Salazar, como parte das celebracións do $800^{\circ}$ aniversario da fundación de Portugal co propósito de conmemorar os feitos históricos e exaltar a mística imperial nacional. Esta elección é, por tanto, moi reveladora, xa que demostra que o presumíbel xénero indíxena da cantiga de amigo considerábase o que mellor recollía a identidade nacional. 
tertextual das cantigas de voz masculina e feminina ${ }^{8}$-que, de maneira un tanto entusiasta de máis, fixo que algúns críticos falaran dunha manifestación de protoheteronimia (Lopes, 2010)- poderían achandar o camiño para unha investigación máis profunda das estratexias retóricas e ideolóxicas que subxacen ao proceso de confiscación vocal que se leva a cabo na cantiga de amigo, o certo é que estas permaneceron até hai moi pouco practicamente inexistentes. Esta ausencia, que ilustra de xeito paradigmático a arraigada desconfianza da academia portuguesa cara aos enfoques orientados ao xénero, parece aínda máis sorprendente cando se confronta co desbordamento da crítica feminista e de xénero angloamericana que, polo menos dende mediados dos anos oitenta, estivo abordando a tradición poética cortesá e, en particular, a canción de muller medieval.

No caso da poesía provenzal, os críticos estabeleceron de maneira convincente a matriz androcéntrica e homosocial do grand chant courtois ${ }^{9}$, destronando así a antiga tese dunha superioridade feminina autorizada poeticamente, e sostiveron ao mesmo tempo que no canso a muller é celebrada só na medida en que dá probas de ser "morally and psychologically androgynous" (Kay, 1990, p. 92); non obstante, a cantiga de amigo peninsular abordouse moi de cando en cando dende a perspectiva dos estudos de xénero. Unha excepción merece ser mencionada: en 1993, baseándose no traballo pioneiro realizado pola medievalista holandesa Ria Lemaire (1988), Ana Paula Ferreira publicou un artigo extremadamente perspicaz -e pasado por alto sen xustificación algunha- titulado Telling Woman What She Wants: As Cantigas de amigo como estratexias de contención. No seu estudo, despois de estabelecer que no contexto poético galego-portugués, "as in other medieval Romance literatures, the fiction of woman's voice cannot be isolated from a whole textual corpus obsessively built around the figure of woman as image" (1993, p. 26), Ferreira sostén que, na cantiga de amigo, a muller "speaks insofar as a male other grants her a reason to do so", e que depende totalmente "upon the male

8 En efecto, era G. Tavani quen, nun estudo publicado orixinalmente en 1980, no Grundriss der Romanischen Literaturen des Mittelalters, destacou por primeira vez a natureza dialóxica de ambos os xéneros, afirmando que "na maior parte dos casos, a cantiga d'amigo apresenta-se como o reverso exacto da cantiga d'amor, seja porque os conceitos aqui expressos pelo poeta na primeira pessoa são os mesmos que, na outra, são atribuídos à mulher, seja porque esta responde, de uma maneira ou de outra, aos lamentos e às solicitações do amante" (Tavani, 2002, p. 196). Para un estado da arte sobre as estratexias de construción dialóxica no traballo das cantigas de amor e cantigas de amigo galego-portugués, véxase Santiago Gómez, 2018, pp. 41-58.

9 Ver, por exemplo, Gaunt, 1995, pp. 122-180. 
gaze for [her] own sense of identity as unitary subject” (pp. 33-34). Baseándose nun exame minucioso dos textos, chega á conclusión de que,

[...] the cantigas d'amigo constitute an ideologically invested, male appropriation of female voice that functioned to support the status quo by confirming women's dependence of the sexual love of men. The image of a desiring female subject could thus have contributed to keep real women from imposing their own alternative voices not only as 'writing', but first and foremost as 'speaking subjects'. (Ferreira, 1993, p. 37)

Entre as amplas manifestacións da vocalidade feminina, ilustradas pola heteroxénea tradición medieval da chanson de femme, o pequeno pero significativo corpus de trobairitz proporcionou un modelo excepcional de contra-dicción feminina, mostrando que "women cannot be contained by masculine structures" (Gaunt, 1995, p. 95). A cantiga de amigo, pola contra, daba conta da manipulación vicaria da voz feminina por mor da cal as palabras da muller non eran máis que un simulacro enxeñoso e unha proxección do desexo do autor masculino que só lle permitía unha voz ficticia para suprimir máis eficazmente a súa representación.

Durante décadas, os estudosos portugueses desaprobaron con desdén a crítica de xénero ao abordar os xéneros medievais galego-portugueses; non é sorprendente que os poetas contemporáneos, en cambio, se desen conta axiña de que os coercitivos guións de xénero postulados polas cantigas ben poderían ser deconstruídos mediante a creatividade, descubrindo así o potencial protofeminista que albergan.

\section{A amiga responde: a voz das mulleres (medievais) na poesía portuguesa contemporánea}

Ese foi certamente o caso da escritora e activista feminista María Teresa Horta, quen, nunha disruptiva colección de poesía titulada Minha Senhora de Mim, que saíu en 1971 para ser pronto confiscada polos censores do réxime do Estado Novo, reciclou a tradición trobadoresca para desacreditar a opresiva política sexual imposta pola ditadura de Salazar. Aínda que se fai eco da vocalización convencional na apelación directa común na cantiga de amor peninsular (mba senhor, o equivalente exacto do epíteto feudal provenzal midons), Horta combínaa coa enunciación feminina convencional da cantiga de 
amigo, para reescribir a posición subalterna da muller que postula a ética-estética do trobador. A voz feminina que fala nos seus disruptivos poemas descorteses, a través dos cales resoa a tradición lírica medieva ${ }^{10}$, non é por tanto a do severo e estereotipado señor nin a da amiga fantasiada polo home, senón que pertence a unha muller con libre albedrío, plenamente consciente do seu propio poder de decisión:

Minha senhora de mim

Comigo me desavim

minha senhora

de mim

sem ser dor ou ser cansaço

nem o corpo que disfarço

Comigo me desavim

minha senhora

de mim

nunca dizendo comigo

o amigo nos meus braços

Comigo me desavim

minha senhora

de mim

recusando o que é desfeito

no interior do meu peito. (Horta, 2009, p. 304)

Logo de confesarse como a súa propia mestra (minha senhora de mim ${ }^{11}$ ), esta muller emancipada e descaradamente erótica é moi consciente do poten-

10 As cantigas medievais non son o único hipotexto do poema de Horta. A súa primeira liña é en realidade unha cita literal dunha coñecida Trova do poeta renacentista Sá de Miranda (1485-1558) que trata o tema do eu dividido por un conflito interior, converténdoo así no seu propio inimigo. Aínda que certamente se sente atraído pola descarada modernidade do texto de Miranda, Horta reformula claramente esta textualidade sincrética á luz das loitas feministas que aborda no seu poema.

11 Anna Klobucka (2009, p. 233) observa acertadamente que no título Minha Senhora de Mim, a reiteración dos pronomes en primeira persoa "ressoavam com uma redundância quase agressiva". 
cial performativo do seu propio discurso e, por tanto, capaz de articular as súas vontades e luxurias até o de agora non expresadas, negándose a ser reducida a unha portavoz poética das fantasías masculinas. Anna Klobucka (2009, p. 234) sinalou con acerto que "a polarização excessiva na figura masculina ausente, característica das cantigas de amigo, chega a ser suprimida aqui pela atenção igualmente obsessiva votada ao eu feminino". A inversión de roles exposta nos poemas de Horta é efectivamente revolucionaria, máis aínda se se considera o contexto ditatorial moralmente represivo no que xurdiu. Nunha especie de volte-face compensatorio, o suxeito feminino fetichiza sen reserva o corpo masculino, utilizándoo como instrumento do seu propio pracer e orquestrando asertivamente os movementos sexuais da súa parella:

\section{O Meu Desejo}

Afaga devagar as minhas

Pernas

Entreabre devagar os meus

Joelhos

Morde devagar o que é

Negado

Bebe devagar o meu

desejo. (Horta, 2009, p. 344)

Ao desmantelar o canon literario e alterar os roles sociais e sexuais, a poética feminista franca de Horta converte o suxeito lírico feminino "em encenador, e já não objecto de encenação, de um encontro sexual, no qual desempenha um papel activo e, segundo a sexualidade mais ortodoxa, passível de ser entendido como desviante" (Amaral, 2017, p. 66). Mediante esta insurrección corporal mediada poeticamente, como resume Ana Luísa Amaral, Horta "desdiz, [...] desmonta, [...] desnomeia" mentres constrúe "novas imagens do corpo".

Unha enerxía libidinosa similar, asimilada coa diferenza ontolóxica feminina, pódese atopar nos elaborados pastiches das cantigas de amigo medievais de Natália Correia. Aínda que orixinalmente se ideou como a "contraparte feminina” complementaria dos seus Sonetos Românticos (1990), Correia admi- 
te, nun breve prefacio explicativo que precede ás dezaoito cantigas, que se deu conta máis tarde de que tanto o masculino como o feminino, como resultado dunha alquimia poética imprevista, se uniron nos proxectados "sonetos masculinos" (Correia, 1999, p. 619). Esta aclaración é certamente reveladora e dá conta do ethos que guía a reelaboración mimética do xénero medieval, seguramente facilitada pola estreita familiaridade de Correia coa obra dos trobadores galego-portugueses ${ }^{12}$. Os textos dispuxéronse en dúas secuencias determinadas polo ton poético, con poemas organizados ao longo dunha dobre vertente de queixume e xúbilo, sendo referendados alternativamente polas "novas amigas" que reviven "velhos cantares de amigo" ou polas "velhas amigas" que cantan "novos cantares de amigo". O quiasmo (novas/velhos; velhas/novos) é indicativo da interacción entre os impulsos anacrónicos e anticuarios en conflito que subxacen nos poemas. Por unha banda, inspíranse en gran medida na fraseoloxía, o simbolismo, as convencións de xénero e mesmo nos patróns dos textos medievais orixinais, abarcando todo o espectro de subtipos tradicionalmente asociados coa cantiga de amigo: as barcarolas, as bailias, a pastoral e a alba. Con todo, este celo mimético vese ás veces socavado pola interferencia de alusións extemporáneas a acontecementos históricos modernos, situando as cuestións expostas polos poemas nun continuo atemporal, e non estritamente medieval. Isto faise explícito dende o primeiro poema, no que, nun escenario aparentemente convencional, un suxeito lírico feminino, de pé xunto ao mar e en dó pola ausencia do seu amado, convida as súas noivas a cantar con ela as vellas cantigas de amigo, coa esperanza de que estas axuden a traer de volta os seus amantes afastados, perpetuamente comprometidos nas guerras:

Nesta praia, amigas, de onde p'rás cruzadas

Foram matar mouros nossos lidadores

Com cantares de amigo chamemos as barcas

Que à lide levaram os nossos amores.

Vão e vêm as ondas. Pelas mesmas águas

Discorrem idades. Não mudam as dores. (Correia, 1999, p. 620)

12 Esta familiaridade maniféstase nunha variedade de ensaios literarios, antoloxías e adaptacións modernas da poesía medieval galego-portuguesa. Entre estas publicacións, as máis influentes foron sen dúbida a escandalosa Antologia de Poesia Portuguesa Erótica e Satírica (1966), que incluía unha selección de poemas satíricos dos trobadores peninsulares, e os Cantares dos Trovadores Galego-Portugueses (1970), nos que Correia presenta versións modernas (ou, máis precisamente, traducións) de setenta e dúas cantigas. 
Ao contrastar o motivo heraclitano das augas que corren coa inexorabilidade da guerra e a iteración do sufrimento humano a través da historia, o retrouso condensa claramente a suxestión subxacente no poema de que, máis aló do seu corsi e ricorsi, xorde fatalmente un patrón familiar de acontecementos, baseado na inmutábel natureza humana. As seguintes estrofas reiteran este argumento, substituíndo a referencia ás Cruzadas medievais por exempla extraídas da historia portuguesa, con mencións aos mariños da Idade dos Descubrimentos ou aos soldados que loitaron nas guerras coloniais africanas.

Esta dialéctica entre a transitoriedade e a permanencia, que impregna todos os poemas, vese reforzada por unha dicotomía de xénero. Mentres que a intervención masculina parece sempre equipararse ás viaxes, á explotación e á destrución, todo iso estimulado pola implacábel rapacidade do home e o seu insaciábel empuxe belixerante, as amigas encarnan unha función restauradora ou homeostática: exhortan os seus amados a abandonar a batalla lembrándolles que chegou a primavera, tratan de evitar os males da guerra coas súas vellas cancións, e mesmo tratan de persuadir aos seus combativos amantes ameazando con deixar de concederlles favores eróticos. Se o amor cortesán medieval era a miúdo un asunto entre homes que deixaba fóra ás mulleres, estas novas cantigas subverten ironicamente esta prerrogativa homosocial e, á inversa, suxiren unha irmandade tácita que con gusto renunciaría á intrusión masculina, se os homes non fosen requiridos para a realización erótica.

Como sinala Evans (2015, p. 111), "sisterhood emphasises relationships between women that are horizontal instead of vertical, avoiding the hierarchy inherent in the mother/daughter trope", que tan insistentemente se tratou na canción de muller galego-portuguesa. O que queda claro é que, nas cantigas de amigo de Correia, a defensa dun ethos matriarcal coincide cun "xenerocidio" simbólico na medida en que pretende suprimir o comportamento falocéntrico violento. Máis que proporcionar unha ilustración poética para o axioma común de que os homes son de Marte e as mulleres de Venus, que se converteu nunha metáfora clixé da diferenza de xénero, as falsas cantigas de amigo de Correia dotan ás mulleres dunha sabedoría transcendente que se traduce nunha ética de pacifismo e harmonía ecolóxica, como ilustra o poema titulado Pastorela:

Ao raiar da manhã estava a bela

Guardando seus mansos cordeiros

Quando nesses ares livres da serra 
A cercaram medonhos guerreiros.

E ouvindo os estrondos da guerra,

Disse a pastorinha aos guerreiros

Que queriam dar cabo de tudo:

Deixai-me em paz nesta serra

Guardar estes mansos cordeiros

Que tiram as maldades do mundo. (Correia, 1999, p. 627)

A utilización das diferenzas de xénero como temáticas poéticas en relación coas actitudes cara á guerra corrobórase coas observacións un tanto esencialistas feitas pola propia Correia nunha entrevista. Despois de afirmar que vivimos nun mundo no que aínda prevalece o poder da palabra do home, ela argumenta que "estruturalmente, a mulher é avessa, alérgica à ideia de guerra e de conflito. A sua própria experiência maternal a predispõe contra a guerra. Dá vida mas não gosta de contribuir para a sua destruição. É por uma actuação pacífica" (Gonçalves, 2004, p. 45). Ao reverter ironicamente o desempoderamento e desprazamento medieval da muller, estes poemas destacan o poder feminino para sublimar sexualmente a violencia masculina. A domesticación da compulsión marcial dos amantes masculinos parece lograr80 se a través do ascenso erótico que as amigas exercen sobre eles, permitindo que frutifique unha xubilosa sensualidade pre-lapsariana, como demostra claramente a alba que pecha a secuencia: nela, despois de espertar nos brazos da súa amada, o guerreiro é persuadido para que non teña en conta o amencer e a chamada á batalla, cambiando "a metralha e ou morteiro" polas "maravilhas" (Correia, 1999, p. 634) ofrecidas pola muller.

A prominencia da cantiga de amigo nas revisións dos xéneros trobadorescos tamén se manifesta no caso de Adília Lopes. Trátase sen dúbida dunha das poetas portuguesas contemporáneas máis controvertidas, xa que Lopes (en relación coa persoa pública e co seu mérito literario) foi idolatrada e ridiculizada en igual medida, até ao fin lograr, especialmente despois da publicación das súas obras poéticas completas en Dobra (2009), a condición de verdadeira poeta de culto. A súa desconcertante e enganosamente sinxela dicción poética $^{13}$, cun distintivo rexistro naïve e infantil, en realidade oculta un sofisticado repertorio de alusións literarias e culturais no que a autobiografía e a fabricación poética se entrelazan de forma provocativa. Rosa Maria Martelo

13 Compárese coas seguintes liñas: "Quanto mais prosaico/ mais poético" (Lopes, 2009, p. 592). 
chamou a atención de maneira penetrante sobre a luxosa "memoria textual" de Lopes, afirmando que,

[...] a memória, em Adília Lopes, é uma memória textual, oral ou escrita, mas textual, o que temos que associar a uma profunda consciência de que não é possível ler o mundo independentemente da sua discursivização. Compreendese, assim, que Adília Lopes esteja sobretudo interessada em confrontar redescrições do mundo. Dessas redescrições, constam tanto referências literárias, poéticas e ficcionais, que se inscrevem na tradição erudita, como todo um vasto campo de mediações discursivas que inclui provérbios, frases-feitas, aforismos, publicidade, adivinhas, programas de televisão, romances cor-de-rosa, ditos familiares, conversas de autocarro e tópicos de revistas femininas". (2010, p. 225)

Entendida como unha crítica posmoderna a unha presunta "genealogia ginocrítica” (Klobucka, 2009, p. 305) da poesía portuguesa, a arqueoloxía literaria de Lopes dá prioridade aos textos canónicos occidentais que tratan a posición discursiva da muller para parodiar o mutismo atávico que se lle impuxo ou o tratamento misóxino unilateral ao que foi sometida repetidamente. Un exemplo típico disto atópase na reescritura irreverentemente burlona das famosas Cartas Portuguesas, inspirando innumerábeis poemas nos que tanto Mariana Alcoforado como o Marqués de Chamilly reciben voces apócrifas que derruban os mitos eróticos sobre os que se construíron os seus personaxes literarios.

En vista diso, non é de estrañar que Adília Lopes se sinta incitada a renovar vellos textos galego-portugueses e, a través deles, a "dedoxify" parodicamente (Hutcheon, 1989) ${ }^{14}$ a convención literaria. Aínda que as cantigas de amigo non son, en absoluto, o intertexto máis omnipresente na súa poesía, as escasas referencias a elas son entusiastamente eloxiosas. Nun fragmento, a medio camiño entre un poema en prosa e unha entrada de diario, incluído en Bandolim (2016), o tema lírico -o cal o lector, moi afeito ao descarado uso da autobiografía por parte de Lopes, relaciona facilmente coa autora- evoca con franqueza as lecturas máis memorábeis da súa infancia, mencionando libros de Juan Ramón Jiménez e Vladimiro Korolenko. As súas observacións finais son inequívocas:

14 O termo "dedoxification", utilizado por Linda Hutcheon, describe o proceso de desestabilización da doxa, é dicir, as crenzas e ideoloxías consensuadas. Véxase Hutcheon, 1989, pp. 10-18. 
Até aos 12 anos, não tinha encontrado na literatura portuguesa textos de que gostasse tanto e que tivessem tanto a ver comigo como Platero e eи e $O$ músico cego. Ainda não encontrei. Continuo na mesma. Só me lembro das cantigas de amigo. (Lopes, 2016, p. 57)

Xa en Sete Rios Entre Campos (1999), as cantigas de amigo foron utilizadas para apoiar unha ars poetica antirretórica e desvirtuar sarcasticamente o uso dun estilo artificial e unha dicción elevada na poesía:

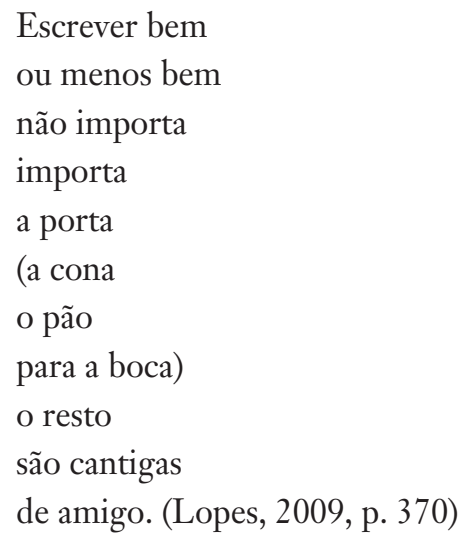

No que podería definirse como unha apropiación pop da tradición lírica medieval, Lopes dá preferencia natural aos textos arquetípicos, é dicir, a aqueles que, en virtude da súa duradeira pegada no imaxinario colectivo e o seu status antolóxico, considera que son os que mellor recollen a tradición poética galego-portuguesa. Esta elección dun corpus moi selectivo e minimalista (cos jograis galegos Martim Codax e Meendinho á cabeza) permite ao lector identificar facilmente os sinais hipotextuais e, ao activar a súa enciclopedia (é dicir, a súa rede de referencias literarias e hábitos interpretativos), pode inferir casos de derivación textual ou de sabotaxe paródico. Ademais, é natural que Adília Lopes se sinta atraída polos minidramas líricos concibidos fai oito séculos por Codax e Meendinho. Autor de sete barcarolas moi aclamadas que se desenvolven en Vigo, Martim Codax organizounas, como sostén Stephen Reckert, "como uma espécie de vilancete semanticamente paralelístico às prestações” (Reckert e Macedo, 1996, p. 165).

Meendinho, doutra banda, é o enigmático autor dunha única, pero verdadeiramente excepcional cantiga de amigo, considerada por moitos unha obra mestra sen parangón na poesía galego-portuguesa. Aínda máis importante é o feito de que ambos desenvolven un guión emocional similar nas súas 
cancións: a amiga planea ansiosamente o encontro erótico, esperando con impaciencia polo seu amante ausente e preguntando ás ondas por noticias, ou ben, como na obra mestra dramática de Meendinho, desespérase ante a perspectiva de que non apareza. A pesar de que se expoñen diferentes escenarios emocionais, todos estes poemas viran ao redor dos temas da nostalxia e a perda, a esperanza erótica e, en última instancia, a frustración.

Desfigurando o patrón formal das cantigas orixinais e desatendendo toda preocupación mimética, Lopes parece máis interesada en desafiar ironicamente a convención do desexo desemparellado e o amor non correspondido que rexe os códigos amatorios medievais da poesía ibérica. Para iso, crea secuelas apócrifas dos poemas compostos por dous xograres que deben considerarse tanto como emendas poéticas como reparacións eróticas aos textos orixinais.

Dous poemas curtos foron inspirados polas barcarolas de Codax:

\author{
De mão dada \\ com o meu amigo \\ vejo os filmes \\ de Jean Vigo. (Lopes, 2009, p. 314)
}

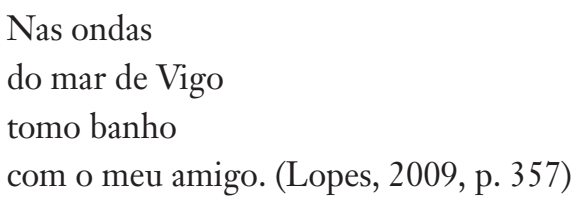

Na súa desconcertante falta de arte, estes poemas fan explícita a predilección de Lopes polo xogo verbal e a contra-textualidade paródica. No primeiro texto, o humor deriva da homonimia de Vigo (o topónimo que indica a localización icónica dos sete poemas de Codax, un verdadeiro depósito de historia e cultura) e Vigo (o apelido do director francés Jean Vigo), un proceso parecido ao annominatio trobadoresco que tamén demostra a predilección de Lopes polos nomes e a alusión cultural. Ademais, a escena da amenidade doméstica da parella de namorados vendo películas da man contrasta notoriamente coa axitación sentimental da expectante amiga de Codax.

A intención revisionista faise aínda máis explícita no segundo poema. A escena de baño evoca claramente a quinta barcarola de Codax na que a moza insta a todas as súas amigas a bañarse con ela no mar en Vigo onde anticipa 
que verán o seu amante ausente. O simbolismo erótico do ritual de baño no mar na tradición galego-portuguesa foi estabelecido dende hai moito tempo polos críticos e non me estenderei nas súas asociacións abertas co pracer sensual e a fertilidade ${ }^{15}$. Adoptando ambos o mesmo motivo, hai, con todo, unha diferenza significativa entre a potencial e anhelada escena de baño representada na cantiga de Codax e a actual, alegre e compartida fruición do mar de Vigo presentada na variante de Lopes. É como se a exhortación expresada pola moza na cantiga medieval de amigo fose finalmente atendida e os seus anhelos eróticos cumpridos. Comentando o remake contemporáneo de Lopes, argumentouse con acerto que ela

[...] aponta para o facto de que, nas cantigas de Codax, falta a efetiva presença do amado, e vai completar a história. Como se ao fim de oito séculos fosse possível à moça apaixonada tomar banho com o seu amigo, no presente do indicativo, $\mathrm{e}$ não mais viver apenas a expectativa da sua chegada no futuro ou a lembrança da sua presença no passado. (Silva, 2017, p. 264)

O mesmo acto de "ingénuo e sofisticadíssimo terrorismo discursivo" (Klobucka, 2009, p. 314) será cometido no soado unicum poético de Meendinho, "Sedia-m'eu na ermida de Sam Simion". Obxecto dun debate filolóxico e un escrutinio literario que se renova continuamente, trátase da única cantiga de amigo de Meendinho que foi reiteradamente eloxiada pola súa impresionante combinación de pathos dramático e logro estilístico. Os críticos chamaron a atención sobre o sutil uso que fai o poeta do simbolismo da onda (Reckert e Macedo, 1996, pp. 146-147), o eficaz “animismo projectivo" (Ferreira, 1999, p. 47), que conecta a figura feminina e a turbulencia da natureza co seu impresionante dominio dos recursos poéticos rítmicos e acústicos. Ademais, subliñaron a orixinalidade do poeta na rexeneración do topo cortesán (masculino) de "morrer de amor" nun poema que capta admirabelmente a vertixinosa transformación emocional que encarna a moza cando se enfronta á adversidade natural e á perspectiva da súa morte inminente. Por tanto, o efecto dramático depende, en gran medida, da estrutura do crescendo poético e da creación de suspense, que culmina no retrouso cuxa problemática interpretación paleográfica deu lugar a numerosas hipóteses ${ }^{16}$. Con todo, calquera que sexa a alternativa que se adopte, o retrouso, xa sexa facendo eco da longa e

\footnotetext{
${ }^{15}$ A este respecto, véxase, por exemplo, Gradín, 1990, pp. 211-213.

16 Para unha visión xeral das diversas teses alternativas e os argumentos contenciosos relativos ás diferentes lecturas do retrouso de Meendinho, véxase, entre moitos outros, Arias Freixedo, 1997, pp. 5-18, e Ferreiro, 2007, pp. 47-67.
} 
infrutuosa espera da amiga a través da duplicación sonora (Eu atendend'o meu amigo/ Eu atendend'o meu amigo) ou rematando interrogativamente a narración (E verrá?) ofrece unha imaxe realista do conmovedor abandono da moza na capela de San Simón, enfrontada a un desexo abafador e á insatisfacción erótica.

Coa súa habitual sinxeleza deflacionista, Adília Lopes responderá poeticamente a Meendinho reducindo drasticamente o pathos dramático do texto orixinal e transformando o que fora unha mera ficción desiderativa nun encontro real:

$$
\text { (pró-Meendinbo) }
$$

Na ermida

de São Simeão

dar-te-ei

a minha mão

meu barqueiro. (Lopes, 2009, p. 362)

Ao presentar a imaxe fantástica do barqueiro rescatando a moza que estaba a piques de ser engulida polas crecentes ondas do mar e que voluntariamente lle dá a man (xogo de palabras), Lopes modifica de maneira conspicua a tradición literaria, tratando de compensar o illamento ancestral feminino ${ }^{17}$. Polo tanto, ser pro-Meendinho (como suxire a paréntese pretextual) significa, máis precisamente, ser pro-muller: ao restabelecer a vontade e a empresa da moza, Lopes libéraa das restricións das convencións, abrindo o camiño para a transitoriedade entre os xéneros e o erotismo consensual alegre. Nun texto abertamente metapoético, incluído en Le Vitrail la Nuit (2006), Lopes anunciara resoltamente:
Acabou
o tempo
das rupturas.
Quero
Ser
Reparadora
de brechas. (Lopes, 2009, pp. 574-575)

\footnotetext{
17 Anna Klobucka sinala con acerto que a cantiga de Meendinho é considerada como "o exemplum máximo da identidade da mulher abandonada e desesperada como uma posição discursiva e existencial paradigmática do sujeito feminino..." (Klobucka, 2009, p. 310).
} 
De feito, o acto de reparar as brechas pode funcionar como a perfecta metáfora da obra poética de Adília Lopes na que a sutura textual e a rectificación revisionista dos discursos canónicos están estreitamente entrelazados.

A colaxe intertextual é tamén un importante procedemento de composición en Bailias, libro publicado pola nova poetisa Catarina Nunes de Almeida en 2010, no que, como se afirma no título, a inspiración trobadoresca ocupa un lugar destacado. É certo que Almeida se sentiu seducida non só polos leitmotifs e a atmosfera sentimental da poesía medieval luso-galega, senón tamén polo cru primitivismo do idioma portugués na elaboración e a calidade melódica das cantigas que, segundo as súas propias palabras, parece anticipar a noción verlainiana da música poética (Boëchat, 2009, p. 233) e que lembra irremediabelmente o concepto poundiano de melopoeia ${ }^{18}$.

Con todo, o lector pronto descobre que a referencia inicial ás bailias galego-portuguesas é, en efecto, unha pista enganosa. En sentido estrito, as bailias de Almeida intercálanse con liñas recorrentes tomadas de outros xéneros poéticos (como a cantiga de amor, a pastoral, a alba, e mesmo a cantiga de escarnio e maldicir), para crear poemas autorreferenciais, altamente cultos e metaforicamente extravagantes. Ao recontextualizar a cantiga de amigo galego-portuguesa, en particular, descarta definitivamente o prexuízo duradeiro que identifica a canción de muller medieval coa Volkspoesie espontánea e sen puír. En Bailias, como resultado dunha excéntrica ars combinatoria postmoderna, as citas familiares das cantigas galego-portuguesas foron desprazadas a unha linguaxe poética na que a densa eludibilidade e os matices moi imaxinativos, ou mesmo surrealistas, se fan omnipresentes.

A conexión inmediatamente discerníbel entre estes poemas, que parecen resistirse á catalogación fácil, e a tradición das cantigas de amigo é, por suposto, a voz feminina. O suxeito lírico de Almeida é moi consciente da súa feminidade e a miúdo expresa unha corporeidade narcisista e xubilosa que parece lembrar as vivaces cancións de baile galego-portuguesas:
Bailam as raparigas
as mãos nas mãos
das raparigas

18 A este respecto, ver McDougal, 1973. 


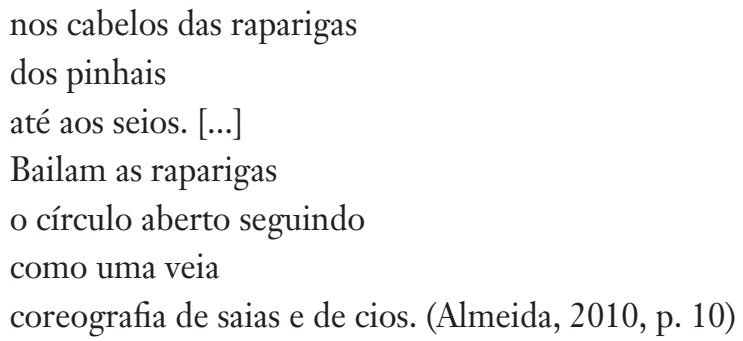

Aínda que ás veces se alude a iso, a intervención masculina é case insignificante nestes poemas nos que a coreografía nupcial das antigas bailias, que serve a un impulso xinecofílico, parece estar menos centrada nos rituais de apareamento e moito máis interesada en celebrar enfaticamente o feminino. Subliñando a influencia tutelar que poetas como Maria Teresa Horta e Luiza Neto Jorge tiveron na súa propia obra poética, Oliveira concede que "de fato, é o meu 'diamante' feminino que me impele para a escrita, por isso, o sujeito feminino continua a ser central. É a partir dele que o erotismo se depura e adquire perspectiva" (Boëchat, 2009, p. 232). Esta "cadência erotica feminina” faise bastante explícita na recreación da cantiga de amor híbrida de Lourenço, o renomeado e polémico jogral portugués, "Tres moças cantavan d'amor", onde o eloxio convencional, dirixido oblicuamente ao poeta masculino, é substituído pola euforia dun encontro nun enclave exclusivamente feminino:

Três moças cantavam d'amor

os braços debulhados dispostos no lençol.

A casa era um corpo

invertebrado.

Um bicho sem concha

à sombra das coxas das moças

que d'amor cantavam

e sobrevoavam o linho

de pernas para o mar

uma de dentro da outra para dentro da outra

e trocavam de sapatos

e teciam véus e vulvas

como quem ensaia a perfeição de um delito. (Almeida, 2010, p.14) 
En consecuencia, a ansiosa espera na que descansaba o dramático núcleo da cantiga de Meendinho foi ironicamente baleirada de todo pathos, xa que agora é a moza quen deliberadamente se afasta do amante ausente. En lugar de fantasiar cun encontro consentido de amantes separados, como imaxina Adília Lopes, a autora de Bailias descarta categoricamente o arquetipo feminino da "Penélope á espera":

Sedia-m'eu na ermida de San Simón
Eu atendend'o meu amigo
morrendo de olhar lá longe
atrevendo-me de longe ao meu amigo
espaçoso e branco
como cavalo branco.

Que o tenha deus lá longe

e cá me deixe viver para o dia

em que me segura o xaile... (Almeida, 2010, p. 24)

Inevitabelmente concisa, esta visión xeral da relación sensíbel dalgunhas poetisas portuguesas contemporáneas coa tradición trobadoresca medieval é, con todo, un bo exemplo do proceso de ajuste de cantos, para recuperar o precepto de Adília Lopes ${ }^{19}$, que permite conciliar as urxencias actuais co paradigma poético que proporciona a lírica medieval, cuxo potencial creativo está claramente lonxe de esgotarse. A conciliación dos cantos medievais cos contemporáneos ditou, en todos os casos examinados, unha (re)semantización radical dos materiais poéticos altamente codificados e vinculados á historia. Non é de estrañar que o impulso subversivo das poetisas contemporáneas se dirixira aos roles de xénero coercitivos e estereotipados que se dramatizaban nos poemas medievais galego-portugueses. Cunha impresionante gama de modulacións poéticas, Maria Teresa Horta, Natália Correia, Adília Lopes e Catarina Nunes de Almeida, á vez que provocaron a rexeneración da cantiga de amigo medieval, sintonizaron as vellas cancións coas novas, postulando un contra-canto feminino: un desafío creativo e de fértil disonancia, grazas ao cal as voces longamente silenciadas das amigas poden volver ser escoitadas.

\footnotetext{
19 Ver nota 1.
} 


\section{Referencias bibliográficas}

Almeida, C. N. de (2010). Bailias. Deriva Editores.

Amaral, A. L. (2017). Do Centro e da Margem: Escritas do Corpo em Escritas de Mulheres. En Arder a Palavra e Outros Incêndios (pp. 61-73). Relógio d'Água.

Arias Freixedo, X. B. (1997). Sobre o refrán da cantiga de Meendinho. Análise das várias hipóteses de lectura. En Actas do Congreso O Mar das Cantigas (pp. 5-18). Xunta de Galicia.

Bec, P. (1979). 'Trobairitz' et chansons de femme. Contribution à la connaissance du lyrisme féminin au moyen âge. Cahiers de Civilisation Médiévale, 87, 235-262. https://doi.org/10.3406/ccmed.1979.2112

Boëchat, V. (2009). 'É muito difícil largar um poema no mundo': entrevista com a poeta Catarina Nunes de Almeida. Revista Desassossego, 2, 229-235. https://doi. org/10.11606/issn.2175-3180.v1i2p229-235

Cohen, R. (2003). 500 Cantigas d'amigo. Campo das Letras.

Corral, E. (2002). Feminine Voices in the Galician-Portuguese cantigas de amigo. En A. L. Klinck e A. M. Rasmussen (Eds.), Medieval Woman's Song (pp. 81-98). University of Pennsylvania Press.

Correia, N. (1999). Poesia Completa. O Sol nas Noites e o Luar nos Dias. Publicações Dom Quixote.

Davis, W. M. (1969). Neo-Troubadourism in Galicia, Portugal, and Brazil [tese de doutoramento]. New York University.

Evans, E. (2015). The Sisterhood: Inclusivity and Spaces. En The Politics of Third Wave Feminisms (p. 111-133). Palgrave Macmillan.

Ferreira, A. P. (1993). Telling Woman What She Wants: The Cantigas d'amigo as Strategies of Containment. Portuguese Studies, 9, 23-38. https://www.jstor.org/ stable/41104973

Ferreira, M. do R. (1999). Águas Doces, Águas Salgadas: da funcionalidade dos motivos aquáticos na Cantiga de Amigo. Granito.

Ferreiro, M. (2007). Sobre a edição dos textos trovadorescos galego-portugueses. Novamente Meendinho. Critica del Texto, X (2), 47-67. http://hdl.handle. net/2183/16009 
Gaunt, S. (1995). Gender and Genre in Medieval French Literature. Cambridge University Press.

Gentry, F. G. e Müller, U. (1991). The Reception of the Middle Ages in Germany: An Overview. Studies in Medievalism, III (4), 399-422.

Gonçalves, Z. C. (Ed.) (2004). Entrevistas a Natália Correia. Parceria A. M. Pereira.

Gutiérrez García, S. (2014). Clerics, Troubadours and Damsels: Galician Literature and Written Culture during the Middle Ages. En H. M. Carballeira (Ed.), $A$ Companion to Galician Culture (pp. 13-34). Tamesis.

Horta, M. T. (2009). Poesia Reunida. Dom Quixote.

Kay, S. (1990). Subjectivity in Troubadour Poetry. Cambridge University Press.

Klobucka, A. (2009). O Formato Mulher. A Emergência da Autoria Feminina na Poesia Portuguesa. Angelus Novus.

Koble, N. e Séguy, M. (2014). Passé présent poésie: um amour de loin. En N. Koble, A. Mussoy e M. Séguy (Eds.), Mémoire du Moyen Âge dans la poésie contemporaine (pp. 5-24). Hermann Éditeurs.

Lemaire, R. (1988). Passions et positions: contribution à une sémiotique du sujet dans la poésie lyrique médiévale. Rodopi.

Lopes, A. (2009). Dobra. Assírio \& Alvim.

Lopes, A. (2016). Bandolim. Assírio \& Alvim.

Lopes, G. V. (2010). Ecos internos na poesia galego-portuguesa: a proto-heteronímia em João Garcia de Guilhade. En I. de Riquer, E. Losada e H. González (Eds.), Professor Basilio Losada. Ensinar a pensar con liberdade e risco (pp. 728-733). Universitat de Barcelona.

Lopes, G. V. (2018). Vozes do silêncio: algumas considerações sobre as mulheres da lírica galego-portuguesa. En E. C. Díaz (Ed.), Voces de mujeres en la Edad Média. Entre realidad y ficción (pp. 340-352). Walter de Gruyter.

López, T. (1997). O neotrobadorismo. A Nosa Terra.

Martelo, Rosa Maria (2010). Adília Lopes. Contra a crueldade, a ironia. En A Forma Informe. Leituras de Poesia (pp. 223-234). Assírio \& Alvim.

Martínez Pereiro, C. P. (2014). 'Mudan-s' os tempos e muda-s' o al'. A varia actualización da poesia trobadoresca no Brasil e na Galiza. En G. V. Lopes e M. Masini 
(Eds.), Cantigas trovadorescas. Da Idade Média aos nossos dias (pp. 89-131). Instituto de Estudos Medievais/Universidade Nova de Lisboa.

McDougal, S. Y. (1973). Ezra Pound and the Troubadour Tradition. Princeton University Press.

Pérez Priego, M. A. (2006). Poetas de la Edad Media y poetas contemporáneos. 1616: Anuario de la Sociedad Española de Literatura General y Comparada, vol. XII, 47-58.

Reckert, S. e Macedo, H. (1996). Do Cancioneiro de Amigo. Assírio \& Alvim.

Roque, A. R. (2018). 'Porque se move a razom [dela]'. A ficção da voz feminina nas cantigas de amigo galego-portuguesas. En E. C. Díaz (Ed.), Voces de mujeres en la Edad Média. Entre realidad y ficción (pp. 362-372). Walter de Gruyter.

Santiago Gómez, C. de (2018). La confluencia del discurso poético: cantigas de amor y cantigas de amigo. Carte Romanze, 6 (1), 41-58.

Silva, S. de S. (2017). Nos passos de Martim Codax: poesia e música em apropriações contemporâneas de cantigas de amigo galego-portuguesas. En J. M. Frias, P. Eiras e R. M. Martelo (Eds.). Ofício Múltiplo. Poetas em outras artes (pp. 261-271). Edições Afrontamento.

Tavani, G. (1988). Propostas para unha nova lectura da cantiga de Mendinho. Grial, XXVI (99), 59-61.

Tavani, G. (2002). Trovadores e Fograis. Introdução à Poesia Medieval Galego-Portuguesa. Editorial Caminho. 